\title{
ZEITSCHRIFT
}

FÜR

\section{KRYSTALLOGRAPHIE UND \\ MINERALOGIE}

UNTER MITWIRKUNG

ZAHLREICHER FACHGENOSSEN DES IN- UND AUSLANDES

HERAUSGEGEBEN

VON

\section{P. GROTH UND E. KAISER}

\section{VIERUNDFÜNFZIGSTER BAND}

MIT 210 FIGUREN IM TEXT UND 13 LITHOGR. TAFELN

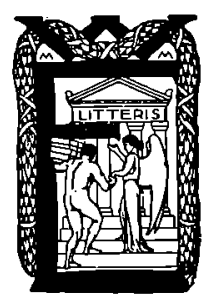

LEIPZIG

VERLAG VON WILHELM ENGELMANN 
.

$-$ 